\title{
Completion Of A Full Course Of Primary Schooling Among All Children Everywhere By 2015: A Case Of Sub-Saharan Africa \\ Robert Wamala, Makerere University, Uganda
}

\begin{abstract}
Achieving the United Nations Millennium Development Goals (MDGs) remains a major challenge, particularly in developing countries. Specifically, achieving the target of completing a full course of primary schooling among all children, which is goal two, is a major challenge for Sub-Saharan Africa. Though literature consensually suggests that the goal will not be achieved by the 2015 target date, no estimates are provided to support these claims. This study seeks to envisage the situation in Sub-Saharan Africa by the target date using an Auto-Regressive Integrated Moving Average (ARIMA) model. The investigation is based on data sourced from the World Bank publication of education indicators for the period 1970-2010. The data, comprising 41 observations, represent the total number of new entrants in the last grade of primary education, regardless of age, expressed as a percentage of the total population of the theoretical entrance age to the last grade of primary education. Overall, an upward trend of completion estimates presented in the results shows that progress has been made in this regard. The success attained for the region following the adoption of the MDGs in 2000 demonstrates that the goal can be achieved. The sub-optimal predictions of the situation obtained in the results nevertheless indicate that the achievement certainly will not be realized by the 2015 target date.
\end{abstract}

Keywords: Millennium Development Goals; MDG; Primary Education Completion Rates; Gross Intake Rate to the Last Grade of Primary

\section{INTRODUCTION}

$\mathscr{I}$ n a 1990 World Conference of Education for All in Thailand, African representatives made a commitment to achieve education for all children by 2000. With the exception of Kenya, South Africa and Zimbabwe, which had achieved this goal before the 1990s (Cynthia \& Paul, 2003), other countries were far from achieving this goal despite progress made in this regard. In affirming the extent of the problem particularly for Sub-Saharan Africa, Cynthia and Paul (2003, pp.4) write, "Education attainment and participation in Sub-Saharan Africa falls significantly below that of all other regions in the developing world." In their study of the cost implications of attaining universal primary completion by 2015, Paul and Meng (2005) do not report otherwise; their study presents Sub-Saharan Africa as the most worrisome region with regard to all children everywhere completing a full course of primary schooling. With a primary completion rate averaging about 53\% among countries in Sub-Saharan region during the 1990s (World Bank, 2001), the World Bank predictions indicating that the rate will remain the same for subsequent years would be highly justified.

In light of the extent of the problem particularly in the Sub-Saharan region, African representatives in the April 2000 World Education Forum agreed to extend the commitment of achieving education for all to 2015 after realizing that the target set for 2000 would not be met. In September that year, 189 nations made a promise to free people from extreme poverty. This pledge turned into the eight Millennium Development Goals (MDGs) with the second goal focusing on ensuring that children everywhere complete a full course of primary schooling by 2015 . The fact that nearly $90 \%$ of the population in Sub-Saharan Africa lives in countries that are totally off-track to attaining universal primary completion by 2015 (Paul \& Meng, 2005) leaves no doubt that the goal will not be 
achieved by the set date. Cynthia and Paul (2003) corroborate research by Paul and Meng (2005) with regard to the failure of the Sub-Saharan region to achieve the education target by 2015. Cynthia and Paul (2003) estimate the number of adolescents (aged 10 to 14) not completing primary school to be about 37 million for the Sub-Saharan region.

A recent 2010 World Bank study comparing regions in terms of education development presents East Asia and the Pacific as a region that has achieved the target of a complete course of primary education for all children. While other regions, such as Europe and Central Asia, Latin America and the Caribbean, as well as the Middle East and North Africa, are reported to be on track for achieving a complete course of primary education for all children, Sub-Saharan Africa and South Asia are observed to be in danger of falling short. The latter regions are reported to have about 100 million school age children (World Bank, 2010). The Sub-Saharan region, in particular, is reported to be lagging farthest behind, with little progress since 1990 (World Bank, 2010).

Although the literature consensually suggests that the goal of attaining a full course of primary schooling for all children in Sub-Saharan Africa will not be attained by 2015, the contentious issue concerns the estimate of future primary completion rate by the set target date. This study uses mathematical approaches based on prior data to estimate future primary completion rates in Sub-Saharan Africa leading up to the target date.

\section{DATA AND METHODS}

The study is based on data sourced from the World Bank publication of education indicators for the period 1970 -2010 (World Bank, 2012). The data comprise 41 records of primary completion estimates of countries in SubSaharan Africa - developing only. The data represent the total number of new entrants in the last grade of primary education, regardless of age, expressed as a percentage of the total population of the theoretical entrance age to the last grade of primary education. In other words, the data represent the gross intake rate to the last grade of primary education in the sub-Saharan region during the period 1970 -2010. The analysis, based on forecasting with Univariate Box-Jenkins models (Pankratz, 2009), was carried out in the following stages:

1. The time series for the gross intake rate (GIR) to the last grade of primary education is summarized using a line plot to provide insight into the nature of, or pattern represented in, the data. Furthermore, an investigation of data stationarity was made using the Dickey-Fuller unit root test. The data were later transformed by differencing to achieve stationarity.

2. A series of Auto-Regressive Integrated Moving Average (ARIMA) models were fitted and tested for stationarity and invertibility conditions, that is, to determine whether they have, respectively, Autoregressive (AR) and Moving Average (MA) coefficients that satisfy mathematical inequalities (Pankratz, 2009). Furthermore, in choosing an appropriate model, the principle of parsimony was put into consideration, thus using the smallest number of coefficients to explain the data

3. Further diagnostic tests on the candidate model adopted for the data (i.e., an autoregressive model of order one (AR (1)) were made with regard to how well it fit the primary completion data; i.e., GIR. The original series was superimposed on the predicted series using a line plot.

4. The residuals generated were tested for normality using a portmanteau white noise test (Pankratz, 2009).

5. Eventually, the approved model was used to predict future primary completion rates for the period 20112015.

\section{RESULTS}

The results of the study are arranged according to three major themes: 1) assessing the stationarity of the data, 2) model estimation and diagnostic tests, and 3) prediction of future completion rate estimates for the period 2011-2015. The subsequent write-up presents a detail of the analysis and results in the above themes.

\section{Trend of Primary Completion Rates}

Figure 1 provides an overview of the time series for the gross intake rate to the last grade of primary education in Sub-Saharan Africa. Overall, the line plot in Figure 1 shows an upward trend in the gross intake rate to 
the last grade of primary education, with primary completion rates expressed as a percentage. Following the adoption of the United Nations MGDs in 2000, Figure 1 shows a steady rise in the proportion of children completing the last grade of primary education from this point onwards.

The fact that the graphic representation in Figure 1 may not provide conclusive evidence of the stationarity condition of the time series, the Dickey-Fuller unit root test was performed to support these conclusions. Results of the stationarity assessment based on the Dickey-Fuller test in Table 1 reveal that the time series is not stationary ( $\mathrm{p}>$ $0.05)$.

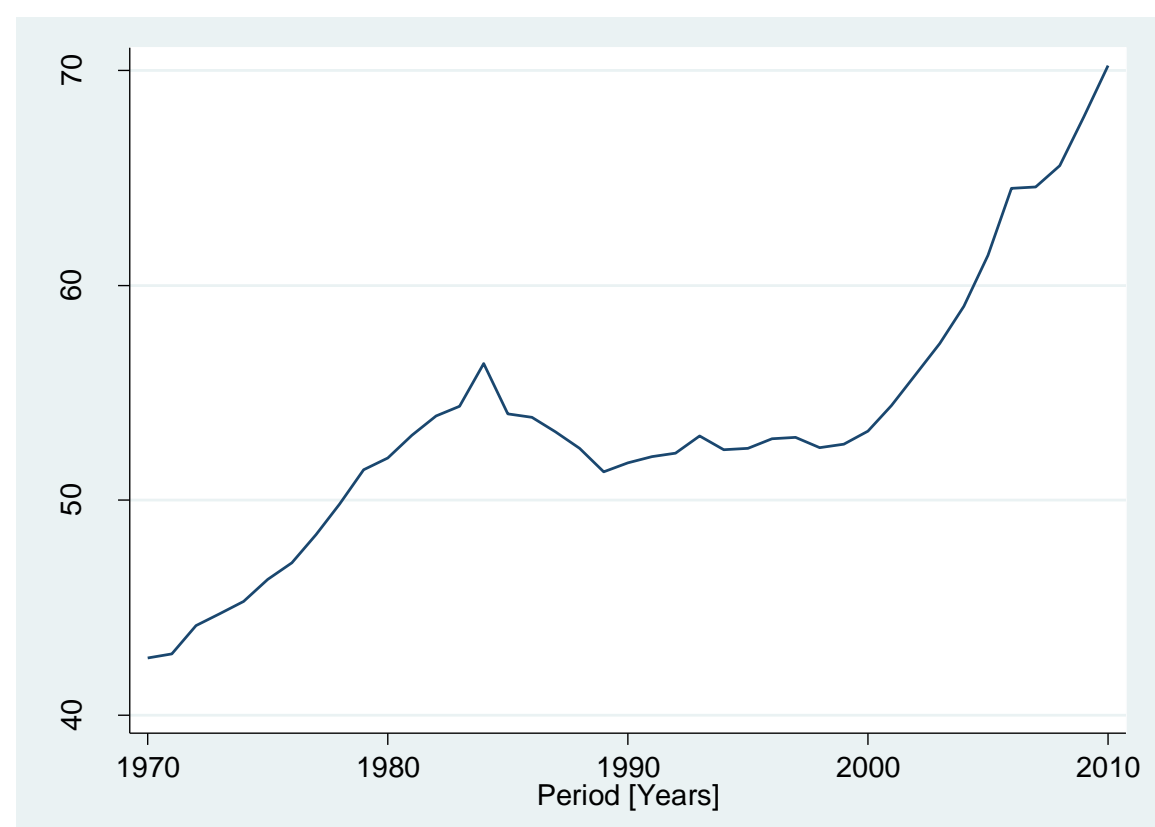

Figure 1: Trend of Primary Completion Rates In The Period 1970-2010 (Annually)

In light of the non-stationarity illustrated in Table $1(\mathrm{p}>0.05)$, the data was transformed by differencing. A stationarity test made on the first-order differenced series presented in Table 2 reveals stationarity of the data ( $p<$ 0.05).

Table 1: Stationarity Test On The Primary Completion Rate Time Series

\begin{tabular}{|c|c|c|c|c|}
\hline \multirow{2}{*}{ Time Series } & \multirow{3}{*}{ Test Statistic } & \multicolumn{3}{|c|}{ Interpolated Dickey-Fuller } \\
\cline { 3 - 5 } & 1.581 & -3.648 & $\mathbf{5 \%}$ Critical Value & $\mathbf{1 0 \%}$ Critical Value \\
\hline $\mathrm{Z}(\mathrm{t})^{\mathrm{a}}$ & & -2.958 & -2.612 \\
\hline MacKinnon approximate $\mathrm{p}$-value for $\mathrm{Z}(\mathrm{t})=0.9978$ & \multicolumn{4}{|c|}{} \\
\hline
\end{tabular}

Note. Unit root test is based on Dickey-Fuller Statistics; Obs. $=41$

${ }^{\mathrm{a}} \mathrm{Z}(\mathrm{t})$ represents Original Series - Primary Completion rate

Table 2: Stationarity Test On Transformed Time Series Of Primary Completion Rate

\begin{tabular}{|c|c|c|c|c|}
\hline \multirow{2}{*}{ Time Series } & \multirow{2}{*}{ Test Statistic } & \multicolumn{3}{|c|}{ Interpolated Dickey-Fuller } \\
\cline { 3 - 5 } & -3.758 & $\mathbf{1 \%}$ Critical Value & 5\% Critical Value & $\mathbf{1 0 \%}$ Critical Value \\
\hline $\mathrm{Z}(\mathrm{t})^{\mathrm{a}}$ & -3.655 & -2.961 & -2.613 \\
\hline MacKinnon approximate $\mathrm{p}$-value for $\mathrm{Z}(\mathrm{t})=0.0034$ & \multicolumn{3}{|}{} \\
\hline
\end{tabular}

Note. Unit root test is based on Dickey-Fuller Statistics; Obs. $=40$

${ }^{\mathrm{a}} \mathrm{Z}(\mathrm{t})$ represents Transformed Series of Primary Completion rate 


\section{ARIMA Model Estimation}

In light of the stationarity condition obtained through transforming the data by adopting a first-order difference, a number of ARIMA models were fitted and investigated for suitability. Table 3 presents a candidate Autoregressive (AR) model adopted for the data, which is later investigated for aptness through a series of diagnostic tests.

Table 3: Autoregressive Estimation Of Primary Completion Rates

\begin{tabular}{|l|c|c|c|c|c|}
\hline \multicolumn{1}{|c|}{$\mathbf{Z}(\mathbf{t})^{\mathbf{a}}$} & Coef. $^{\mathbf{b}}$ & Std.Err $^{\text {c }}$ & p-value & \multicolumn{2}{c|}{$\mathbf{9 5 \%}^{\mathbf{C}} \mathbf{C l}^{\mathbf{d}}$} \\
\hline cons & 0.708 & 0.327 & 0.030 & 0.067 & 1.350 \\
\hline AR(1) & 0.407 & 0.153 & 0.008 & 0.107 & 0.707 \\
\hline sigma & 0.951 & 0.083 & 0.000 & 0.788 & 1.115 \\
\hline
\end{tabular}

Note. Fitted model is ARIMA (1, 1, 0); Wald Chi-square $=7.10, p$-value $<0.01$

${ }^{\mathrm{a}} \mathrm{Z}(\mathrm{t})$ - represents Transformed Series of Primary Completion rate, i.e., differenced series

${ }^{\mathrm{b}}$ Coef. - represents coefficients in the model - ARIMA $(1,1,0)$

${ }^{\mathrm{c}}$ Std.Err - represents standard errors of estimates

d $95 \%$ CI - represents the $95 \%$ confidence interval of the coefficients

${ }^{\mathrm{e}} \mathrm{AR}(1)$ - represents regression coefficient of first-order lag in the model

\section{Regression Diagnostics}

Three diagnostic tests were made on the AR model presented in Table 3. First, using in-range predictions estimated by the model, an investigation was made of how well the estimated model predicts the completion rate data. According to Figure 2, showing both the original and predicted series, the model fits the data fairly well.

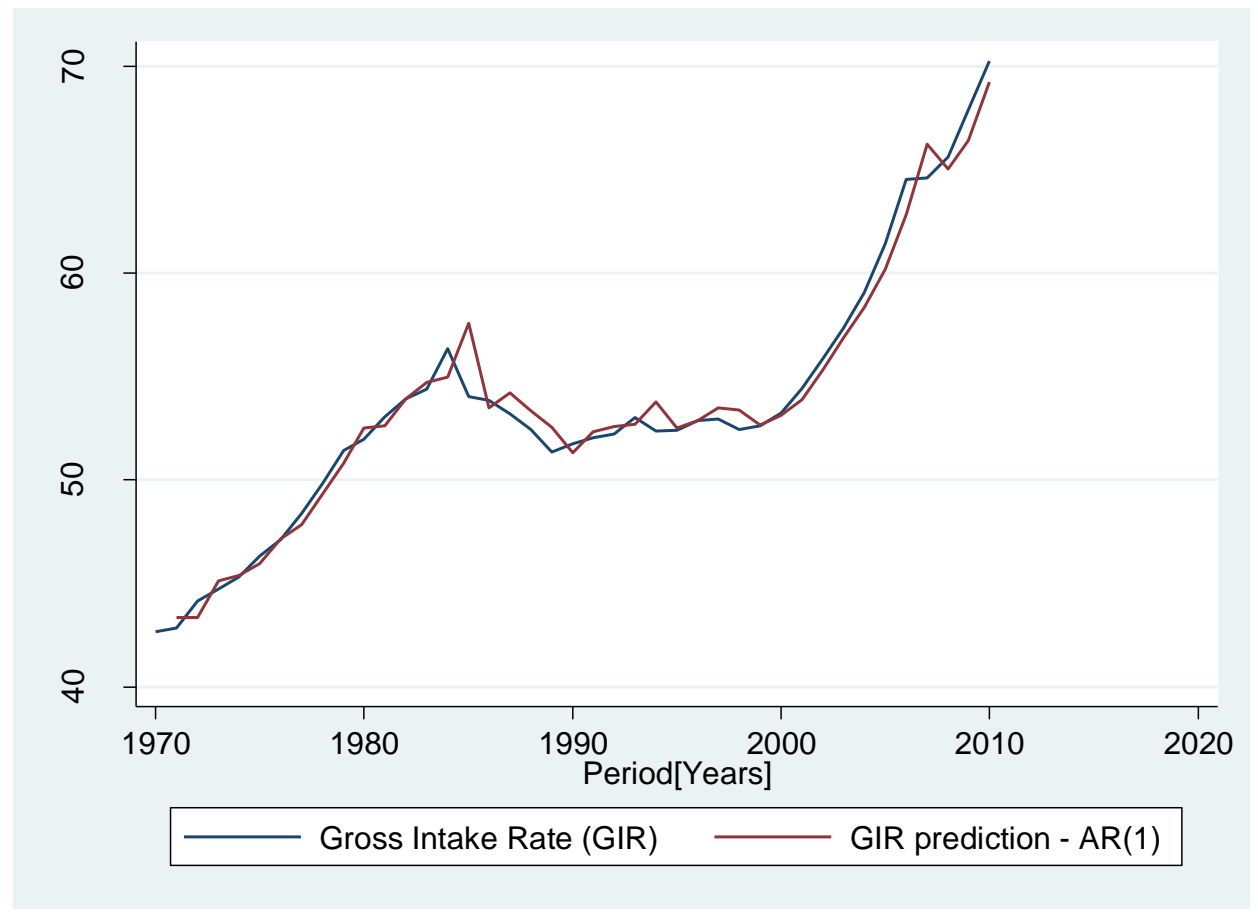

Figure 2: Comparison Of GIR Series And Predicted Data Series Using The Model

Secondly, the estimated AR coefficient presented in Table 3 satisfies the stationarity condition for the firstorder autoregressive model (AR (1)); i.e., $|\mathrm{AR}(1)|<1$. The model is always invertible since an AR regression is fitted. 
Thirdly, a plot of the cumulative periodogram white noise test shows that the values (dotted points) never appear outside the confidence bands. This implies that the generated residuals are white noise $(p>0.05)$ and allows the conclusion that the residuals are independent. The results of the portmanteau white noise test for normality of residuals do not show otherwise $($ Portmanteau $(\mathrm{Q})$ statistic $=17.20, \mathrm{p}=0.509)$.

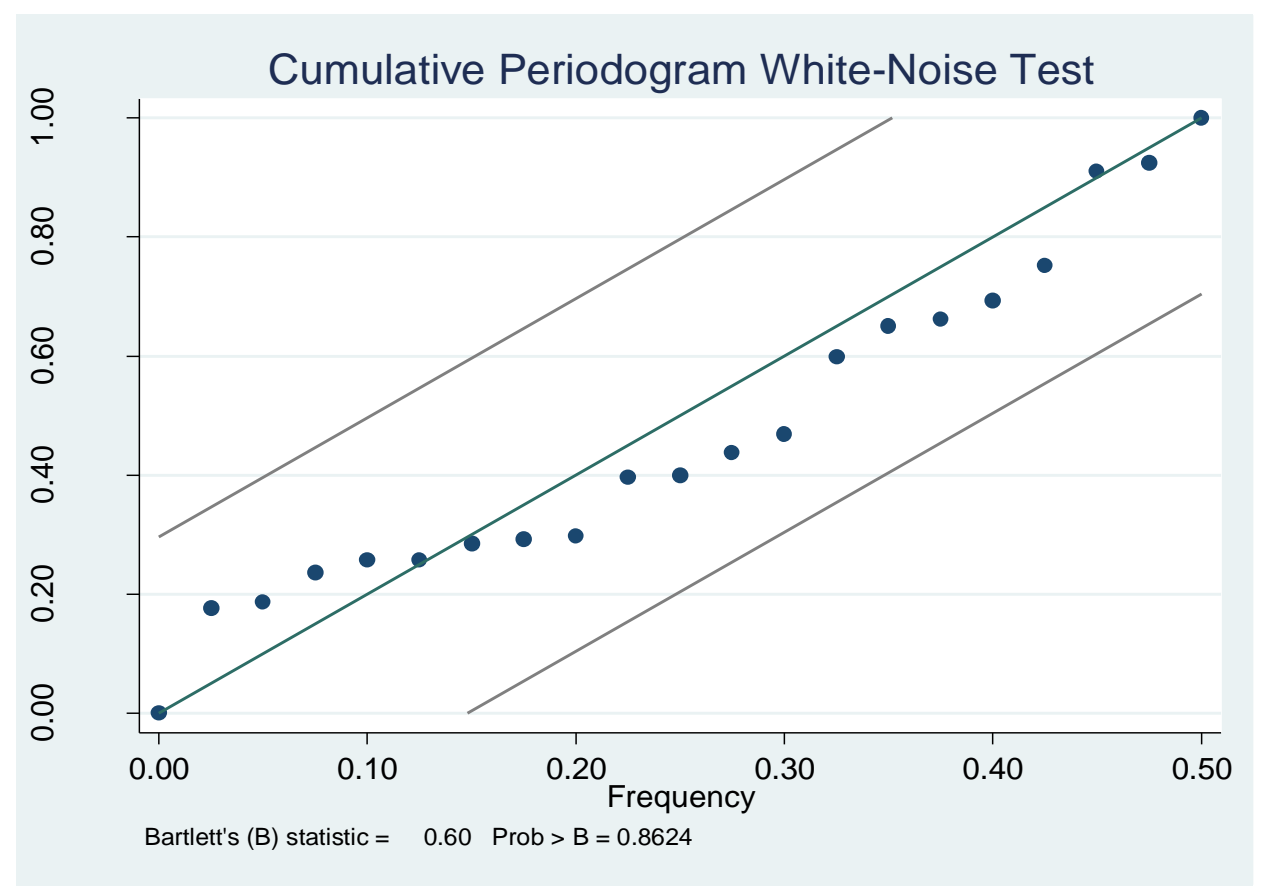

Figure 3: Cumulative Periodogram White Noise Test

\section{Predicting for the Period 2011-2015}

Figure 4 shows out-of-sample predictions for the gross intake rate to the last grade of primary education for the years from 2011 to 2015; the forecasts are $71.60 \%, 72.58 \%, 73.41 \%, 74.16 \%$, and $74.89 \%$, respectively. The predictions leading up to the 2015 target date show progress towards achieving the goal of having children in SubSaharan Africa complete a full course of primary education. However, the sub-optimal estimates point to a low capacity of education systems in the region towards curbing dropouts and/or improving retention - keeping children in school to complete their primary education. Nevertheless, the results show that the completion rate is expected to rise steadily, but optimal completion of a full course of primary school among all children in Sub-Saharan Africa will not be attained by 2015 . 


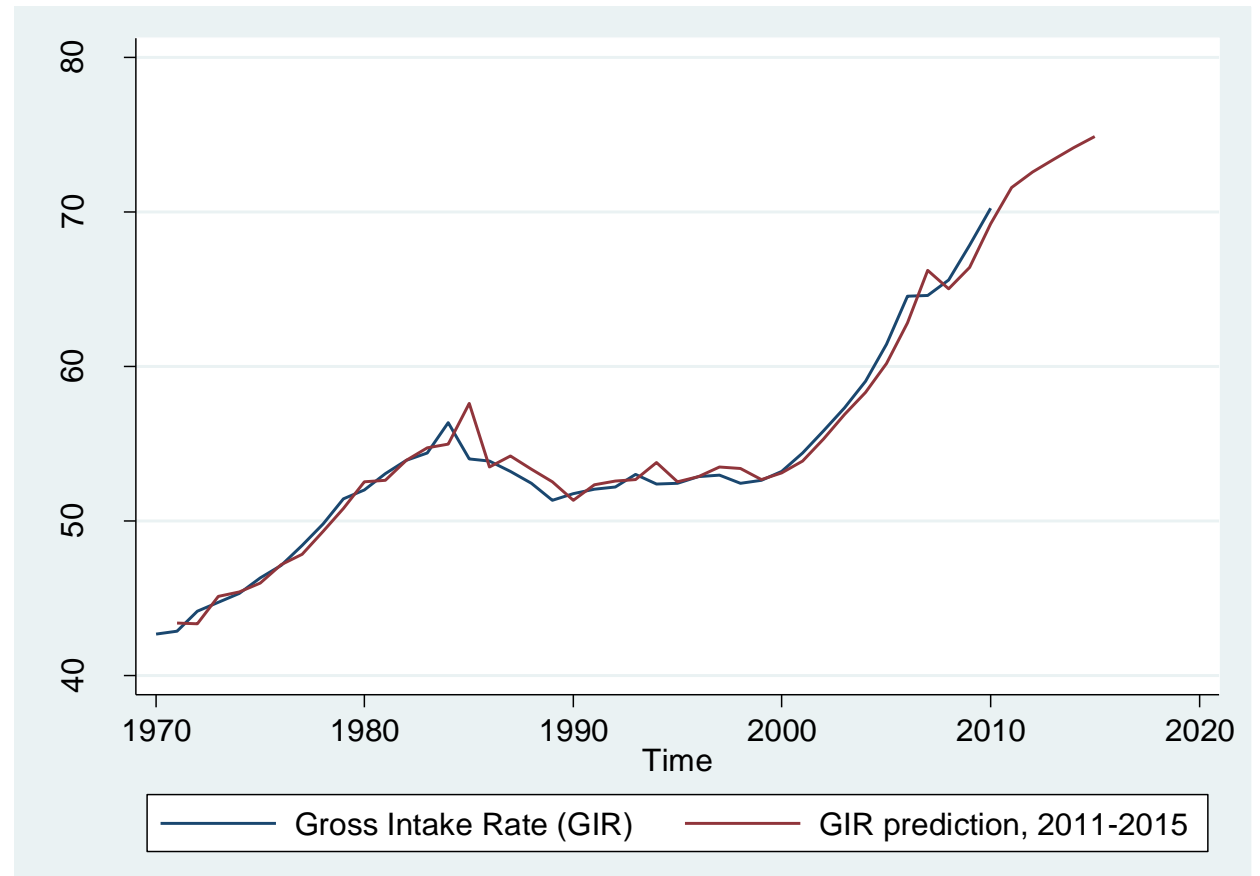

Figure 4: Out-of-Sample (2011-2015) Annual Predictions Of Gross Intake Rate (GIR) To The Last Grade Of Primary Education

\section{DISCUSSION}

The upward trend of the primary completion rates observed in the results shows that progress has been made toward having all children in Sub-Saharan Africa complete a full course of primary education. In the postcolonial period during the 1960 s and 1970s, a steady rise in primary completion rates could be attributed to the importance accorded to schooling in national development plans (NDP), which led to a sharp increase in education expenditure and tremendous expansion of educational infrastructure (Word Bank, 1988; Kinyanjui, 1993). The inability of countries in the Sub-Saharan region to maintain levels of educational outcomes in the 1980s and 1990s has been attributed mainly to 1) lagging growth of investment in education (Kinyanjui, 1993; Nieuwenhuis, 1996), 2) continuing growth in size of school age cohorts (Kinyanjui, 1993; Nieuwenhuis, 1996; UN, 2001), and 3) political instability and/or internal conflicts (Kinyanjui, 1993). Evidently, a steady rise in the completion rates is observed following the adoption of the United Nations MGDs in 2000.

The 2015 prediction made in this study for children in Sub-Saharan Africa (i.e., 74.89\% primary completion rate) affirms recent studies suggesting that the goal of having all children everywhere complete a full course of primary education will not be attained by the target date (e.g., Cynthia \& Paul, 2003; Paul \& Meng, 2005; World Bank, 2010). The estimates made for the period 2011-2015 nevertheless suggest that the completion rates are expected to increase steadily in subsequent years.

In sum, the success attained in achieving a full course of primary education among children in Sub-Saharan Africa demonstrates that the goal can be achieved but will not be realized by the 2015 target date. All the same, countries in the sub-Saharan region must accelerate efforts toward maintaining the upward trend of primary completion rates noted in the results.

\section{AUTHOR INFORMATION}

Dr. Robert Wamala, Ph.D. School of Statistics and Planning, Makerere University, Uganda. E-mail: rwamala@isae.mak.ac.ug 


\section{REFERENCES}

1. Cynthia, B. L., \& Paul, C. H. (2003). Primary schooling in Sub-Saharan Africa: Recent trends and current challenges. Policy Research, 176. Population Council. Retrieved from http://www.popcouncil.org/pdfs/wp/176.pdf

2. Kinyanjui, K. (1993). Enhancing women's participation in the science-based curriculum: The case of Kenya. In: J. K. Conway, \&S. C. Bourque, (Eds.). The politics of women's education: perspectives from Asia, Africa, and Latin America. Ann Arbor: University of Michigan Press

3. Nieuwenhuis, F. J. (1996). The development of education systems in post-colonial Africa: A study of a selected number of African countries. Pretoria: Human Science Research Council Publishers.

4. Pankratz, A. (2009). Forecasting with univariate Box - Jenkins models: Concepts and cases. New York: John Wiley \& Sons

5. Paul, G., \& Meng, Z. (2005). Attaining universal primary completion by 2015: How much will it cost? Proceedings of the American Academy of Arts and Science. Retrieved from http://faculty.apec.umn.edu/pglewwe/documents/UBASECs6_05.pdf

6. United Nations. (2001). World population prospects: The 2000 Revision, Volume 1: Comprehensive Tables. New York: United Nations, Department of Economics and Social Affairs, Populations Division.

7. World Bank. (1988). Education in Sub-Saharan Africa: Policies for adjustment, revitalization and expansion. Washington, DC: World Bank.

8. World Bank. (2010). Education opens doors. Education Resources. Retrieved from http://siteresources.worldbank.org/INTPRH/Resources/education.pdf

9. World Bank. (2012). World Bank development indicators. Retrieved November 2012 from http://data.worldbank.org/indicator/ SE.PRM.CMPT.ZS 


\section{NOTES}

